1 Universidade Estadual de Londrina (UEL) - Londrina (PR), Brasil.

prvolponi@hotmail.com

2 Universidade Estadual de Londrina (UEL) Londrina (PR), Brasil. maragara@hotmail.com

3 Universidade Estadual de Londrina (UEL) Londrina (PR), Brasil. brigidagimenez@gmail.com

\section{Núcleo de Apoio à Saúde da Família: potencialidades como dispositivo de mudança na Atenção Básica em saúde}

\author{
Family Health Support Nucleus: potentials as change device in \\ Primary Health Care
}

Paula Roberta Rozada Volponi1, Mara Lúcia Garanhani2, Brigida Gimenez Carvalho ${ }^{\mathbf{3}}$
RESUMO O artigo analisa a potencialidade do Núcleo de Apoio à Saúde da Família (Nasf) para constituir-se em dispositivo de mudança nas práticas de cuidado e nos modos de atuação de uma equipe gestora da Atenção Básica. Estudo de abordagem qualitativa, de caráter compreensivo, realizado junto aos gestores da Diretoria de Atenção Primária à Saúde de município de grande porte do Paraná, no período de setembro/2012 a abril/2013, por meio de observação e entrevistas. Os resultados revelaram predominância do objetivo estratégico do Nasf enquanto dispositivo, que a gestão colegiada se mostrou um arranjo potente para a gestão e, por fim, que a implantação do Nasf pode ser compreendida como uma ação que potencializa a produção de mudanças na Atenção Básica.

PALAVRAS-CHAVE Gestão em saúde; Atenção Primária à Saúde; Saúde da família.

ABSTRACT The article analyzes the potentiality of the Family Health Support Nucleus to establish itself as changing device in primary care practices and in the performance ways of a primary care management team. It's a qualitative approach study, of sympathetic character, performed with the Primary Health Care Board managers of a large size municipality of the Parana State, from September/2012 to April/2013. The results revealed predominance of the Family Health Support Nucleus's strategic objective while a device, that the collegiate management showed as a powerful arrangement for the management and, finally, that the Family Health Support Nucleus implementation can be understood as an action that enhances the production of changes in Primary Care.

KEYWORDS Health management; Primary Health Care; Family health. 


\section{Introdução}

No contexto atual da produção do cuidado no Brasil, permanece a necessidade de busca por mudanças substantivas na dinâmica das organizações de saúde, em especial, nos modos de produção do cuidado.

Contudo, não estamos nos referindo a qualquer mudança, e sim à construção de um processo de fortalecimento da dimensão pública e social das organizações de saúde, que expressa a defesa da saúde como um direito do cidadão e dever do Estado. Essas mudanças possibilitariam novas formas de organização dos serviços e renovação dos processos de gestão, proporcionando a democratização das instituições, com maior participação dos agentes e melhoria em seus resultados (AZEVEDO, 2010).

Para alcançar os objetivos desta mudança, permitindo a construção e a disponibilização de uma caixa de ferramentas para os gestores, é necessário viabilizar, propiciar e experimentar determinados arranjos institucionais que sejam facilitadores de novos processos de comunicação e coordenação no âmbito das instituições (CECíLIO; MERHY, 2003). Tais arranjos devem permitir, ao mesmo tempo, a incorporação da inteligência já produzida e a de novos saberes, possibilitando uma atuação competente em relação aos processos de produção, que sempre emergem em fluxos de grande incerteza.

Tais mudanças exigidas e impressas nos processos de trabalho também geram novas exigências para os trabalhadores, uma vez que abalam as formas tradicionais do exercício de funções, papéis, responsabilidades e desempenhos, assim como as formas de interação. Tais mudanças acarretam a necessidade de adequações nos processos, nas condições de trabalho e, sobretudo, na busca por novos conhecimentos, habilidades e métodos de atuação em equipe (SANTOS-FILHO; BARROS, 2009).

Para se consolidar as mudanças pretendidas, devem-se buscar dispositivos de mudanças capazes de mobilizar e impactar as práticas hegemônicas em saúde, imersas em um cenário de desvalorização dos serviços públicos e de precarização das condições de trabalho, mergulhado em sentimentos de impotência, de descrença, de impossibilidade de mudança, de apatia e conformismo (AZEVEDO, 2010).

Para Onocko Campos (2003), tais dispositivos buscam subverter as linhas de poder instituídas. Como exemplo de dispositivos, podem ser citadas oficinas de planejamento, cursos/treinamentos/formação, análise/supervisão institucional, assembleias etc. Estes dispositivos devem estabelecer um padrão de relacionamento que propicie outras formas de experimentação da grupalidade, que não seja a de relação do outro como ameaça, como depositário de tudo que é ruim.

Além dos dispositivos, Onoko Campos (2003) distingue os arranjos como forma de instalar espaços na organização. Estes têm certa estruturação e permanência. Assim, podem ser institucionalizados, para que possam operar com potencialidade, em fluxos contínuos contrários à produção baseada no controle. Apresenta como arranjos: o colegiado de gestão, que impõe uma mudança estrutural nas linhas de mando, eliminando gerências, coordenações ou direções especializadas, como um espaço de deliberação e discussão clínica; o apoio matricial, como um suporte especializado, desvinculado da linha de mando; e a Equipe de Saúde da Família (EqSF), equipe de referência que se corresponsabiliza pelo usuário, criando vínculo, com a prerrogativa de coordenar o cuidado.

Inseridas nesta discussão, há reflexões que apontam que o caminho para a mudança está pautado em uma tarefa do conjunto dos trabalhadores de saúde, no sentido de modificar o cotidiano do seu modo de operar o trabalho no interior dos serviços de saúde (MERHY, 2013), e em novos modos de gestão em saúde (ARAÚJO; PONTES, 2012). Tais mudanças devem ter capacidade de construir novos pactos de 
convivência e novas práticas, aproximando os serviços dos conceitos de atenção integral, humanizada, de qualidade, e equânime, e dos demais marcos dos processos de reforma do sistema de saúde brasileiro (CECCIM, 2005).

Nessa perspectiva, o governo brasileiro, desde a década de 1990, vem tomando iniciativas para reorientar o modelo de atenção à saúde a partir da Atenção Básica (AB), com a Estratégia Saúde da Família (ESF). Esta estratégia deve estar inserida em um contexto de gestão democrática e participativa, pautado no trabalho em equipe, direcionado às populações de territórios definidos, utilizando tecnologias de cuidado complexas, a fim de manejar as demandas e necessidades de saúde de forma eficiente (BRASIL, 2012).

Dentro deste contexto, os Núcleos de Apoio à Saúde da Família (Nasf) foram instituídos pelo Ministério da Saúde em 2008 (BRASIL, 2008), com a intencionalidade de se alcançar a integralidade do cuidado e a interdisciplinaridade das ações em saúde, de maneira a apoiar e complementar o trabalho da ESF.

É neste sentido que o Nasf, inspirado no apoio Paidéia - metodologia que busca reformular os tradicionais mecanismos de gestão, voltada à formação de pessoas com capacidades ampliadas para analisar e intervir sobre as relações sociais (CAMPOS; CUNHA; FIGUEREDO, 2013), constitui-se em proposta estratégica para auxiliar na mudança das práticas. Tem a perspectiva de atuação em gestão colegiada e criação de vínculos para que, de maneira prática, seja possível combinar autonomia e responsabilidade.

O Nasf é composto por profissionais de diferentes áreas do conhecimento. Tem atuação pautada no trabalho em equipe, com a função principal de apoiar a EqSF, aumentando sua resolubilidade (CUNHA; CAMPOS, 2011). Enquanto apoiador matricial das equipes de referência, também é visto com potencialidade para se tornar um dispositivo da gestão, para fomentar a rede de serviços em saúde (SAMPAIO ET AL., 2012).

Desta forma, com base na ideia de que alguns dispositivos potencialmente concretos para uma mudança nos modos de produção do cuidado e na gestão em saúde devem ser gerados, emerge a indagação: $\mathrm{O}$ Nasf tem potencialidade para se constituir enquanto dispositivo de mudança nas práticas de cuidado e de gestão?

Diante do exposto, o presente trabalho busca analisar essa possibilidade, a partir das ações desenvolvidas por uma equipe gestora da $\mathrm{AB}$, de um município de grande porte.

\section{Método}

Tratou-se de um estudo com uma abordagem qualitativa, de caráter compreensivo e interpretativo. É um recorte da dissertação de mestrado intitulada 'Implantação dos Núcleos de apoio à saúde da família: atuação da equipe gestora da atenção', realizado em um município de grande porte do sul do Brasil.

Foram incluídos no estudo, profissionais integrantes da equipe gestora municipal, que, na época da coleta de dados, exerciam cargos oficiais na Diretoria de Atenção Primária à Saúde (Daps), e profissionais do Nasf. Esta equipe é formada pela diretoria de $\mathrm{AB}$, assessorias técnicas, gerências regionais de Unidades Básicas de Saúde (UBS), gerências de programas especiais, coordenadorias dos ciclos de vida e coordenadores de UBS.

O período de coleta de dados compreendeu os meses de setembro a dezembro de 2012, final da gestão municipal 2009-2012, e os meses de fevereiro a abril de 2013, início da gestão 2013-2016.

Os instrumentos metodológicos escolhidos foram: observação participante e entrevista semiestruturada. Entre entrevistados e participantes, nos momentos observados, a pesquisa contou com o envolvimento de 58 pessoas. Entre elas, 48 exerciam cargos de gestores formais ( 15 eram da diretoria da $A B$ e 31 , coordenadores de UBS) e 12 eram profissionais do Nasf (membros do colegiado gestor e participantes de reuniões presenciadas). 
A observação, registrada em diário de campo, foi realizada no ambiente de trabalho dos diferentes atores da pesquisa, de modo a permitir maior interação entre pesquisador e participantes. Foram 98 horas de observação de reuniões e atividades do cotidiano, distribuídas nos 5 meses de coleta de dados. Em relação aos encontros, observaram-se, principalmente, as reuniões semanais dos gestores da Daps (40h), os grupos de trabalho e preparação de oficinas (8h), as reuniões mensais da equipe da Daps com as coordenadoras de UBS (8h), reunião de gestores com os Nasf (4h), reuniões do colegiado gestor ( $8 \mathrm{~h})$ e as reuniões das gerentes regionais com as coordenadoras de UBS e com o Nasf (20h).

As entrevistas individuais, entre o pesquisador (entrevistador) e os gestores (entrevistados), foram realizadas entre os meses de fevereiro e abril de 2013; gravadas e, posteriormente, transcritas, com a autorização dos participantes. Nessa fase, também foram registradas informações em diário de campo, relacionadas a expressões e atitudes dos entrevistados ou a outros aspectos considerados relevantes. A entrevista foi guiada por um roteiro que abordou a caracterização dos entrevistados e as ações desenvolvidas no processo de implantação do Nasf. Tomou-se o cuidado de utilizar um ambiente confortável e silencioso, com menores possibilidades de interferências e interrupções externas. Buscou-se a criação de um clima favorável, que deixasse o entrevistado à vontade para responder aos questionamentos.

Foram entrevistados 15 gestores. Entre os entrevistados, 11 estavam ligados ao nível central da Daps: a diretoria (1), todas as gerências regionais (6), as assessorias técnicas (2), a gerência de programas especiais (1) e a coordenação do ciclo de saúde da criança e aleitamento materno (1). Foram entrevistadas também quatro coordenadoras de UBS da região da qual a equipe gestora apontou o Nasf que desenvolvia, com maior eficiência, o trabalho relacionado ao apoio matricial. Não se entrevistou o coordenador da ESF e Nasf, pois o cargo estava vago no momento da pesquisa.

As entrevistas estão identificadas pela letra G, acompanhadas de um símbolo numérico, de 1 a 15, e escolhidas aleatoriamente.

Na primeira fase da análise, foram realizados procedimentos de leitura flutuante, com exploração do material transcrito, a fim de conhecer o texto e se deixar invadir por impressões e orientações. A fase de exploração do material consistiu na administração sistemática das decisões tomadas na fase anterior, na qual realizamos leitura aprofundada de cada entrevista, seguida da produção de análise individual das mesmas, e de uma síntese. Após a conclusão das 15 sínteses, os resultados foram agrupados em dois espaços de gestão: os gestores formais alocados na Daps (diretores, assessores e gerentes) e os alocados nas UBS (coordenadores). Na última fase, com os resultados significativos, foram propostas inferências e realizaram-se interpretações com base nos objetivos traçados. O diário de campo foi utilizado como suporte para a construção da análise e interpretação das entrevistas. Ao longo do trabalho, os trechos oriundos dessa fonte de pesquisa estão identificados com as letras DC, seguidas das datas do registro.

O projeto desta pesquisa foi aprovado pelo Comitê de Ética em Pesquisa da instituição em que estão inseridos os pesquisadores, cadastrada com Certificado de Apresentação para Apreciação Ética (CAAE) $n^{\circ}$ 06127012.7.0000.5231, aprovada sob Parecer $\mathrm{n}^{\mathrm{o}}$ 93.228. Também foi autorizado pela Secretaria de Saúde do município pesquisado.

\section{Resultados e discussão}

Os 15 profissionais entrevistados eram todos enfermeiros e contratados sob o regime estatutário. Houve predominância do sexo feminino (14); tempo de atuação superior a 2 anos, com variação até superior a 15 anos. Apresentavam, em sua maioria, experiência 
em cargos de coordenação de UBS (13), gerências regionais (8) e assessoria técnica de enfermagem (5). Todos tinham formação complementar: em saúde da família (8), saúde coletiva (6) e educação profissional (7).

Os resultados estão apresentados em duas categorias: (1) Nasf: dispositivo de mudança e (2) Colegiado gestor: um arranjo com potencialidades para a mudança.

\section{Nasf: dispositivo de mudança}

A investigação possibilitou apreender que o Nasf foi assumido como uma estratégia inovadora (G1, G3, G7, G9), com potencialidades criadoras de novas práticas no cotidiano dos serviços (G1, G2). Tais práticas foram apontadas como possíveis contribuições para a efetivação das desejadas mudanças no trabalho em saúde e na produção do cuidado.

O processo de trabalho do Nasf foi orientado pelas diretrizes do Ministério da Saúde (G1, G2, G5, G9), com adaptações às necessidades do município (G2, G4, G8). Assim, o trabalho foi organizado com base no compartilhamento e no apoio às práticas em saúde, em especial, no reforço às seguintes diretrizes: a ação interdisciplinar e intersetorial; a educação permanente em saúde; a educação popular; o território; a integralidade; o controle social; a promoção da saúde; e a humanização. As equipes têm orientação para priorizar nove áreas estratégicas: atividade física/práticas corporais; práticas integrativas e complementares; reabilitação; alimentação e nutrição; saúde mental; serviço social; saúde da criança/adolescente e do jovem; saúde da mulher; e assistência farmacêutica (BRASIL, 2010).

O trabalho desenvolvido pelos profissionais do Nasf possibilitou o repensar dos gestores sobre a produção de trabalhadores sujeitos, autônomos e protagonistas, além do fortalecimento de vínculos e a coparticipação e corresponsabilização na gestão democrática e participativa, o que gerou diferentes posicionamentos a esse respeito.

Esses resultados estão em consonância com o conceito de Nasf apresentado por alguns autores: como um dispositivo inovador, capaz de potencializar as ações das equipes da ESF e de confrontar desafios a serem enfrentados na AB (SILVA ET AL., 2012). Assim, se constitui em dispositivo fundamental para assegurar integralidade ao cuidado e resolutividade à $\mathrm{AB}$, especialmente, por intervir na cultura dos encaminhamentos. Possibilita, concomitantemente, promover uma discussão sobre a formação dos profissionais em saúde.

Os gestores visualizaram avanços com a chegada do Nasf. Houve referência de que muitos dos programas que não existiam no município, agora existem por mérito do Nasf (G2). Para eles, houve uma ampliação do olhar para a produção do cuidado (G2, G3) e um aumento no cardápio de ações oferecidas pela UBS (G5, G13) aos seus usuários, relacionadas à atenção aos ciclos de vida anteriormente pouco assistidos; aos novos grupos terapêuticos; ao desenvolvimento do apoio matricial; e à ampliação de ações de prevenção e promoção. Houve também relatos sobre o impacto nas doenças crônicas (G2, G14) e na melhoria da qualidade de vida da população assistida (G1, G12), com destaque para a atuação de dois profissionais, o nutricionista e o profissional de educação física. Entre as novas atividades realizadas, citou-se o trabalho com a obesidade infantil, a depressão, grupos de coluna, caminhadas e atividades com idosos (G2).

[...] já vi avanços nesse último ano, porque nós trabalhamos a questão do matriciamento [...] Nós observamos também o grande trabalho do Nasf junto à população com ações de prevenção e promoção à saúde, com impacto nas doenças crônicas e melhora na qualidade de vida da população. Especificamente, observo o nutricionista fazendo isso muito claramente, o educador físco com essa possibilidade de promover saúde a 
grupo de idosos, de gestantes, crianças com obesidade [...]. (G1).

Desta forma, as ações praticadas citadas se relacionam com os principais desafios do Nasf, no que se refere a melhorar a qualidade do serviço ofertado e não apenas suprir a demanda assistencial (NASCIMENTO; OLIVEIRA, 2010).

Em relação aos avanços no processo de construção para a integralidade do cuidado, foi citado um caso que envolveu uma situação de luto, em que a atuação dos profissionais do Nasf junto à equipe desencadeou uma reflexão sobre o processo de trabalho. Essa reflexão contribuiu para que fossem vislumbradas novas possibilidades de atuação dos profissionais, com vistas à integralidade do cuidado.

Uma coisa que para mim marcou, foi a questão do luto. É muito comum, na unidade de saúde, se chegar alguém passando mal, alguém já vai pedindo para ver a pressão e sai falando: morreu marido da fulana e ela está passando mal. Eaí, vem uma psicóloga e diz para mim: 'É normal, ela está nervosa ela tem que chorar, faz parte do luto'[...] Para nós, não. Já dá o remédio, já vê pressão, já vê consulta com cardiologista [...] e não entende a questão toda que permeia aquela hipertensão. (G2).

Foi referido que a construção do processo de trabalho do Nasf acontece no cotidiano do serviço, por erros e acertos, apoiada em avaliações realizadas, coletivamente, por representantes da gestão da Daps, da gestão local e dos profissionais do Nasf.

É com a experiência mesmo do dia a dia. A gente vai fazendo, vê o que dá certo, o que não dá, faz avaliações. Então, normalmente, a gente faz avaliações regionais [...] com o Nasf para avaliar como estão as atividades, como estão se desenvolvendo, o que pode mudar, o que pode melhorar, o que tem que acrescentar. (G15).

A partir dos resultados, inferimos que o Nasf se caracterizou como um dispositivo de mudança, uma vez que, para a concretização de seus objetivos, ou seja, para a integralidade da produção do cuidado e a interdisciplinaridade, foram criados novos padrões de relacionamento, que propiciaram outras formas de experimentação de grupalidade. Eles provocaram certos incômodos no modo de se operar no interior dos serviços, produziram reflexões das práticas, estabeleceram novas parcerias.

Deve-se entender que um dispositivo de mudança tem dois momentos essenciais: o da predominância de um objetivo estratégico; e o da produção de efeitos positivos, negativos ou indesejados, por meio de uma relação de ressonância e de contradição, que exige rearticulações e reajustes de elementos que surgem, de forma dispersa, em um processo contínuo de preenchimento estratégico (FOUCAULT, 2006).

Enquanto dispositivo de mudança, apresentou maiores avanços em um dos dois momentos essenciais a essa condição, o momento da predominância do objetivo estratégico. Isso se deu principalmente na institucionalização de alguns espaços, como as reuniões de matriciamento, nos momentos de reuniões com a EqSF e nos encontros formais com os gestores. Podem se relacionar a esse momento algumas contribuições: a deflagração do uso do apoio matricial; a instituição de arranjos para a reorganização das relações de poder e para a configuração de espaços mais democráticos e participativos (com análise, negociação e intervenção); e avaliações das práticas cotidianas.

Em relação ao segundo momento de um dispositivo - o da produção de efeitos positivos, negativos e indesejados -, percebeu-se que algumas ações e concepções relacionadas ao trabalho do Nasf encontraram ressonância entre os gestores e foram capazes de produzir efeitos positivos. Como exemplo disso, podemos citar: a ampliação do olhar para a produção do cuidado; o aumento no cardápio de ações oferecidas pela UBS aos seus usuários; a construção para a integralidade do cuidado; e a ampliação de ações para a promoção da saúde e para a diminuição do 
impacto de doenças crônicas, como estratégia para a melhoria da qualidade de vida dos usuários. Quando não houve ressonância, foram produzidos efeitos indesejados e, até mesmo, negativos, como a demonstração de indiferença por parte de alguns gestores quanto à relevância do trabalho do Nasf.

Desse modo, o Nasf foi se transformando em uma produção viva em ato, permeado por disputas de poder, desejos e necessidades.

\section{Colegiado gestor: um arranjo com potencialidades para a mudança}

Observamos que a formação do colegiado gestor do Nasf foi impulsionada pela dificuldade no processo de gestão do trabalho do próprio Nasf. O espaço falho no organograma da diretoria - expresso pela falta do coordenador do Nasf - somado à postura passiva de alguns coordenadores de UBS em relação à definição de direcionamentos para as ações e atividades a serem desempenhadas pelo Nasf e a resistência destes coordenadores em assumir a gestão, resultou nesse arranjo. "[...] A gente tem, no organograma aqui da prefeitura, um coordenador de saúde da família e do Nasf. Só que, até hoje, não conseguiu alocar ninguém. Por questões inúmeras" (G2).

O colegiado se formou pela indicação de um componente de cada categoria profissional do Nasf, todos embasados em critérios e características individuais de pró-atividade e habilidades para discutir e direcionar o trabalho. Os participantes se reúnem em fóruns de discussão, que, inicialmente, proporcionam o debate de políticas públicas, em especial, das relacionadas ao Nasf. Esse modo de operar contribui para as discussões das funções a serem desempenhadas pelos profissionais e favorece a formulação de protocolos de assistência, direcionados a cada categoria profissional, embasados em uma visão de apoio e retaguarda assistencial especializada.

[...] Cada categoria sempre tem alguém que se destaca, tem mais iniciativa, é pró-ativo. Então, a gente chamou esses que se destacavam de cada categoria: farmacêutico, psicólogo, nutricionista, fisioterapeuta e educador físico. Fizemos uma reunião e montamos o colegiado, e demos carta branca. 'Vocês vão ajudar a gente a direcionar o trabalho do Nasf'. Criaram-se fóruns de discussões. Eles começaram a produzir o protocolo. Criaram-se fóruns locais e reuniões mensais de Nasf, com, pelo menos, uma enfermeira da unidade. E tem os fóruns regionais. (G2).

Os gestores apontaram o colegiado como algo inovador (G1, G5), uma alternativa ao modo de gerir o trabalho do Nasf e, também, como uma forma de disseminar as decisões tomadas no coletivo e aproximar-se da gestão central (G4). Aos olhos do gestor, sua atuação na gestão se aproxima à dos gerentes regionais no que se refere à deliberação, ao poder de decidir.

A gente criou um grupo gestor, acredito ser algo inovador. Não sei se, no Brasil, tem ou não tem [...] Cada categoria tem um representante [...] para discutir um pouco mais aprofundado as políticas de saúde, [...] as políticas específicas do Nasf, para a gente disseminar melhor pelos grupos. Porque são 50 profissionais [...] O grupo gestor, ele já faz um trabalho como gerente, como um coordenador regional. Essa era uma ideia nossa, a princípio [...]. (G1).

O colegiado do Nasf foi visto por alguns gestores como um arranjo com potencialidade para buscar alternativas frente à permanência de práticas hegemônicas pelos novos profissionais, e para revelar interesses em disputas nas UBS, como, por exemplo, o desejo de que o Nasf realizasse o apoio e o trabalho compartilhado em equipe com a ESF (G7, G9); ou o desejo do atendimento clínico especializado à demanda (G12, G13).

No entanto, observamos que o colegiado também vem se constituindo em espaço que propicia: o controle das atividades 
desenvolvidas nas UBS; a disseminação, entre equipes e categorias profissionais, de informações sobre as decisões dos gestores; e a elaboração de 'receitas' sobre como construir o trabalho do Nasf, em um movimento de criação de linhas de conduta e estruturação do trabalho. Desta forma, o espaço do colegiado possibilita, ao representante do nível central da gestão, imprimir um forte direcionamento às atividades a serem desenvolvidas pelo Nasf. O trecho do diário de campo ilustra esta ponderação.

O encontro se inicia com o questionamento sobre os avanços nas sistematizações dos grupos, em um tom de controle/cobrança do cumprimento de tarefa anteriormente solicitada. A maioria das falas é voltada ao coordenador do grupo. (DC 13/03/2013).

A este respeito, Cecílio (2010) nos afirma que há dificuldades quanto às concepções, às formas de organização e ao funcionamento de colegiados gestores como instrumentos para a inovação da gestão. Neste estudo, visualizamos que os profissionais não conseguiram concretizar o colegiado como espaço efetivo de participação, de negociação, decisão e pactuação.

Também observamos que alguns dos profissionais membros do colegiado se apresentam com 'olhares analisadores ruidosos' sobre o modo como vêm se constituindo as práticas em saúde pelos profissionais do Nasf, sobre suas tecnologias e direcionalidades, e sobre o modo de fazer gestão presente no cotidiano do serviço. Entretanto, esses ruídos parecem, algumas vezes, ignorados e sobrepostos, no momento do encontro, pelo 'tarefismo', resultante da estrutura funcionalista da organização. Observa-se uma disputa de poderes, que respeita a hierarquia e abafa os ruídos, ao invés de deixá-los aflorar. Esta prática deixa passar a oportunidade de publicizar e problematizar as situações cotidianas, nem sempre possibilitando a discussão coletiva e a busca de novos caminhos.

Profissionais ' $A$ ' e ' $B$ ' demonstram preocupação sobre o possível engessamento das estratégias a serem utilizadas nos grupos, com a padronização, e Ihes é explicado que o objetivo é criar linha-guia, conduzir o caminho e direcionar os novos profissionais, evitando prolongar a discussão. (DC 13/03/2013).

Constatamos, também, que o colegiado foi criado para auxiliar os gestores da Daps de forma mais consultiva, possibilitando a expressão das opiniões dos profissionais que auxiliassem na tomada de decisão de tais gestores, o que corrobora as ideias de Cecílio (2010).

Notamos que, para alguns profissionais do Nasf, o colegiado foi visto apenas como um espaço para transmissão de diretrizes do nível central, a serem cumpridas localmente, reforçando uma conotação autoritária para o colegiado. Além disso, por vezes se configurou como espaço para que o corporativismo se manifestasse, pois o representante no colegiado se revestia de porta-voz de sua categoria profissional, nem sempre atingindo a adequada articulação entre os representantes e seus representados.

Para analisar os modos de gestão, tomamos emprestados os conceitos de gerir e de gerar apresentados por Onocko Campos (2003, P. 124). $\mathrm{O}$ gerir se relaciona à gestão clássica, como a "ação sobre as ações dos outros", e se relaciona ao controle, à regulação e às normatizações. Pode, também, estar ligado ao exercício de poder disciplinado, que tem grande preocupação com a produtividade e forte tendência a reproduzir as práticas vigentes. $\mathrm{O}$ gerar estaria relacionado à busca, a movimento, à desestabilização do instituído. Abriria, para gestão, um lugar e um tempo. Criaria e instituiria espaços para a experimentação de tomadas de decisões coletivas e criação de projetos. Espaços como instâncias reflexivas e com análises implicadas com o que se pretende produzir (ONOCKO CAMPOS, 2003).

Podemos destacar que os gestores vislumbraram, na gestão colegiada, a possibilidade de este se constituir em um arranjo potente para a gestão. Ressaltamos que o colegiado gestor se estabelece como um 
arranjo ao se tornar uma forma de organização institucionalizada, com certa estruturação e permanência, com potencialidade para produzir fluxos na direção contrária (ONOCKO CAMPOS, 2003).

Porém, apesar de a intenção da equipe gestora ter vislumbrado a dimensão do gerar com esse arranjo, criando e instituindo um espaço para a experiência de tomada de decisão coletiva, e possibilitando a formulação de projetos coletivos, a dimensão do gerir parece ter predominado no colegiado do Nasf.

Percebemos que a dimensão do gerir pode se relacionar à instituição dos protocolos como forma de chefiar a produção de atos e procedimentos, e pela necessidade de controle sobre o produto do Nasf no cotidiano dos serviços. Isto pode ser relacionado ao forte perfil de controle de alguns membros do colegiado, que, por diversos momentos, comprometeu a dimensão do gerar desse arranjo de gestão.

Diante do exposto, deve-se destacar que apenas a instituição do colegiado de gestão, por si só, não garante a distribuição de poder e o estabelecimento de espaços de decisão legitimados por todos os profissionais de saúde, conforme é defendido por alguns autores (CECÍLIO; MENDES, 2004).

Portanto, ficou evidente que as potencialidades do gerar, desse arranjo, não estiveram a salvo de serem capturadas pela predominância do gerir dos serviços de saúde, o que corrobora a proposição de que toda coisa que um dia se institucionaliza, não está a salvo de ser capturada pela lógica dominante (ONOCKO CAMPOS, 2003).

Desse modo, percebeu-se a convivência entre o desejo da mudança e suas dificuldades, em um movimento de avanço e retrocesso no confrontamento com o processo instituído. $\mathrm{O}$ retrocesso pode se relacionar ao estabelecimento da construção de protocolos por categoria profissional, com a pretensão de provocar mudanças de modo controlado, e os avanços podem ser traduzidos como uma nova possibilidade de inventar modos de gerir, com profissionais na disputa por projetos embasados na necessidade dos usuários e em uma postura pró-ativa de mudanças.

Com base nas ideias de Cecílio (2007), acredita-se que o ponto de partida de toda pretensão de mudança, na forma de fazer gestão e organizar o cuidado, deve se relacionar à capacidade de interrogar o mundo do trabalho antes de propor, a priori, conceitos e/ou modos prescritivos de fazer a gestão. É necessário (des)construir categorias/conceitos/ sentidos, em um encontro capaz de provocar discussão, debate, diálogo, de forma espontânea e não sistematizada, em um processo de criação e operação de novas categorias e conceitos que façam sentido para a prática.

Assim, para que o Nasf se potencialize enquanto dispositivo inovador nos processos de mudança, em busca da produção do cuidado integral e da satisfação das necessidades de saúde da população, há de se investir na garantia de espaços que promovam o encontro; possibilitem o diálogo; potencializem as ações das equipes da ESF; problematizem as ações cotidianas; favoreçam ações compartilhadas e corresponsáveis; deixem aflorar os conflitos; e estimulem novas reflexões e o desenvolvimento de estratégias criativas para novos e velhos problemas de saúde. Além disso, deve estar integrado às equipes da ESF com interação dos núcleos dos saberes, o que possibilitaria a construção de contratualizações das relações de trabalho; a horizontalização de relações de poder capazes de aglutinar certas habilidades que estão no campo da tensão entre os modelos e os processos de trabalho; o agenciamento e a aproximação das pessoas envolvidas; e o favorecimento de espaços de conversa e negociação.

Devem-se manter arranjos que visem a modos de gerir amparados em princípios democráticos, que não excluam a dimensão do autogoverno, mas considerem a potencialidade de todos os envolvidos no processo e explorem o espaço permanente de tensões, conflitos e disputas. Arranjos amparados em formalismos contratuais, que delegam poder e potencialidade de mudança a poucos, não garantem 
o compromisso e o comprometimento necessários para os processos de mudança. As organizações precisam ser consideradas como espaços mutantes de construção permanente e inacabada (ACIOLE, 2013).

Os dispositivos e arranjos deflagrados necessitam, assim, ser pensados a partir dos seus verdadeiros instituintes, os usuários.

Convém expor que o estudo limitou-se a explorar o olhar dos gestores formais da $\mathrm{AB}$. Apesar de serem uma parcela importante dos atores na gestão, devemos considerar que não representam a totalidade da visão. Assim, acreditamos que futuros estudos possam apreender outras impressões, incluindo a visão de outros atores envolvidos no processo. Houve a intencionalidade de discutir os resultados sob a ótica de um dado referencial, porém outros estudos podem ser analisados sob outras perspectivas teóricas.

\section{Conclusão}

O presente trabalho procura demonstrar que a implantação/implementação das equipes Nasf se constituiu como um dispositivo com a potencialidade de instituir mudanças nos processos de trabalho e na produção do cuidado. O Nasf e os arranjos implementados a partir deste dispositivo foram, em alguns momentos, capazes de cumprir seu papel, por interrogar os processos de trabalho e as produções do cotidiano, e por trazer novas disputas para o cenário. Em outros momentos, foi utilizado para a manutenção do status quo.

\section{Referências}

ACIOLE, G. G. As desventuras de público no país dos privatas. In: FERLA, A. A.; RAMOS, A. S.; LEAL, M. S. C. (Org.). VER-SUS Brasil: caderno de textos do VER-SUS/ Brasil. Porto Alegre: Rede Unida, 2013.
Por se tratar de uma política recente, os resultados desta pesquisa tornam-se relevantes, pois analisam o Nasf enquanto um dispositivo de mudança, com potencialidades criadoras de novas práticas, com capacidade de ampliar e intensificar as ações das EqSF, de deflagrar processos e de instituir novos arranjos na AB. Além disso, apresenta possibilidades na gestão do seu processo de trabalho, por meio da instituição de arranjos, como o colegiado gestor, uma possibilidade na dimensão 'gerar' da gestão.

O processo de busca por mudanças é favorecido quando há constituição de dispositivos e arranjos que utilizam decisões compartilhadas e pactuadas, com foco na consecução do objetivo comum: a atenção à vida e a produção do cuidado integral e de qualidade. Assim, para que se efetivem transformações, deve-se ousar e investir no potencial de mudança do Nasf enquanto dispositivo, e, no colegiado gestor, enquanto arranjo. Eles devem ser mantidos de forma criativa e como alternativas aos fazeres atuais no cotidiano dos serviços, com a ampliação da capacidade de interrogar tais fazeres e com investimento na garantia de espaços que proporcionem o encontro.

Acreditamos que os resultados desta pesquisa trazem à tona concepções e ações desempenhadas pelos gestores da $\mathrm{AB}$ no município pesquisado. A reflexão sobre estas concepções e ações contribui para a compreensão de movimentos em um processo de mudança. Destacamos as alternativas de rompimento de práticas hegemônicas em favor de processos instituintes, visando a modos de alcançar a integralidade do cuidado.
ARAÚJO, C. E. L.; PONTES, R. J. S. Constituição de sujeitos na gestão em saúde: avanços e desafios da experiência de Fortaleza (CE). Ciênc. Saúde Colet., Rio de Janeiro, v. 17, n. 9, p. 2357-2365, 2012. 
AZEVEDO, C. S. A dimensão imaginária e intersubjetiva das organizações de saúde: implicações para o trabalho gerencial e para a mudança organizacional. Ciênc. Saúde Colet., Rio de Janeiro, v. 15, supl. 1, jun. 2010.

BRASIL. Ministério da Saúde. Secretaria de Atenção à Saúde. Departamento de Atenção Básica. Diretrizes do NASF: Núcleo de Apoio a Saúde da Família. Brasília, DF: Ministério da Saúde, 2010.

Ministério da Saúde. Secretaria de Atenção à Saúde Departamento de Atenção Básica. PNAB: Política Nacional de Atenção Básica. Brasília, DF: Ministério da Saúde, 2012.

Ministério da Saúde. Secretaria de Atenção à Saúde. Portaria ${ }^{\circ} 154$, de 24 de janeiro de 2008. Cria os Núcleos de Apoio à Saúde da Família - NASF. Diário Oficial [da] União. Brasília, DF, 24 jan. 2008. Disponível em: <http://bvsms.saude.gov.br/bvs/saudelegis/gm/2008/ prt0154_24_01_2008.html>. Acesso em: 25 out. 2015.

CAMPOS, G. W. S.; CUNHA, G. T.; FIGUEIREDO, M. D.

Praxis e formação Paidéia: apoio e co-gestão em saúde. São Paulo: Hucitec, 2013.

CECCIM, R. B. Apresentação. In: BRASIL. Ministério da Saúde. Secretaria de Gestão do Trabalho e da Educação na Saúde. Departamento de Gestão da Educação na Saúde. Curso de Formação de facilitadores em educação permanente em saúde: orientação para o curso. Rio de Janeiro: FIOCRUZ; Brasília, DF, Ministério da Saúde, 2005.

CECILIO, L. C. O. Colegiados de gestão em serviços de saúde: um estudo empírico. Cad. Saúde Pública, Rio de Janeiro, v. 26, n. 3, mar. 2010.

O "trabalhador moral” na saúde: reflexões sobre um conceito. Interface - Comunicação, Saúde, Educação, Botucatu, v. 11, n. 22, p. 345-351, maio/ago. 2007.

CECILIO, L. C. O.; MENDES, T. C. Propostas alternativas de gestão hospitalar e protagonismo dos trabalhadores: porque as coisas nem sempre acontecem como os dirigentes desejam? Saúde Soc., São Paulo, v. 13, n. 2, p. $39-55,2004$
CECÍLIO, L. C. O.; MERHY, E. E. O singular processo de coordenação de hospitais. Saúde em Debate, Rio de Janeiro, v. 27, n. 64, p. 110-122, maio/ago., 2003.

\section{CUNHA, G. T.; CAMPOS G. W. S. Apoio Matricial e} Atenção Primária em Saúde. Saúde Soc., São Paulo, v. 20, n. 4, p. 961-970, 2011.

FOUCAULT, M. Microfisica do poder. 22. ed. Rio de Janeiro: Ed. Graal, 2006.

MERHY, E. E. Em busca do tempo perdido. In: FRANCO, T. B; MERHY, E. E. Trabalho, produção do cuidado e subjetividade em saúde. São Paulo: Hucitec, 2013, p. 19-67.

NASCIMENTO, D. D. G.; OLIVEIRA, M. A. C. Reflexões sobre as competências profissionais para o processo de trabalho nos Núcleos de Apoio à Saúde da Família. Mundo Saúde (Impr.), São Paulo, v. 34, p. 92-6. 2010.

ONOCKO CAMPOS, R. A gestão: espaço intervenção, análise e especificidades técnicas. In: CAMPOS, G. W. S. Saúde Paidéia. São Paulo: Hucitec, 2003.

SAMPAIO, J. et al. O NASF como dispositivo da gestão: limites e possibilidades. Revista Brasileira de Ciências da Saúde, João Pessoa, v. 13, n. 3, p. 317-24. 2012.

SANTOS-FILHO, S. B.; BARROS, M. B. Trabalhador da Saúde: muito prazer! Protagonismo dos trabalhadores na gestão do trabalho em saúde. Ijuí: Editora Unijuí, 2009.

SILVA, A. T. C. et al. Núcleos de Apoio a Saúde da Família: desafios e potencialidades na visão dos profissionais da atenção primária do município de São Paulo, Brasil. Cad. Saúde Pública, Rio de Janeiro, v. 28, n. 11, p. 2076-2084, nov. 2012.

Recebido para publicação em maio de 2015

Versão final em outubro de 2015

Conflito de interesses: inexistente

Suporte financeiro: não houve 